\title{
A formação cultural como ferramenta básica do Design:
entrevista com Norberto Chaves ferramenta básica do Design:
entrevista com Norberto Chaves
}

ENTREVISTA

The cultural formation as a basic design tool: interview with Norberto Chaves

Daniela Velleda Brisolara http://lattes.cnpq.br/8981479558198156

Karina Pereira Weber http://lattes.cnpq.br/5493103088912010

Louise Gonçalves da Luz http://lattes.cnpq.br/8053433457750330

Entrevista realizada em 28 de julho de 2016 com Norberto Chaves, professor, pesquisador e participante ativo dos Congressos de Ensino de Design da Universidad de Palermo (Buenos Aires, Argentina), concedeu-nos essa entrevista após suas várias palestras realizadas neste evento. Suas falas permearam as temáticas de cultura, marcas, formação do designer e papel do design no contexto socioeconômico e cultural. $\mathrm{O}$ autor esclareceu que o design, desde sempre, possui funções importantes para a economia. Fora desse contexto, o design perde o foco de sua existência, uma vez que nasceu nesse contexto: com fins de contribuir para o desenvolvimento econômico e no modo de vida dos indivíduos. Portanto, enquadra-se como um produto cultural, sobretudo porque faz parte da comunicação, ação inerente aos seres humanos. 


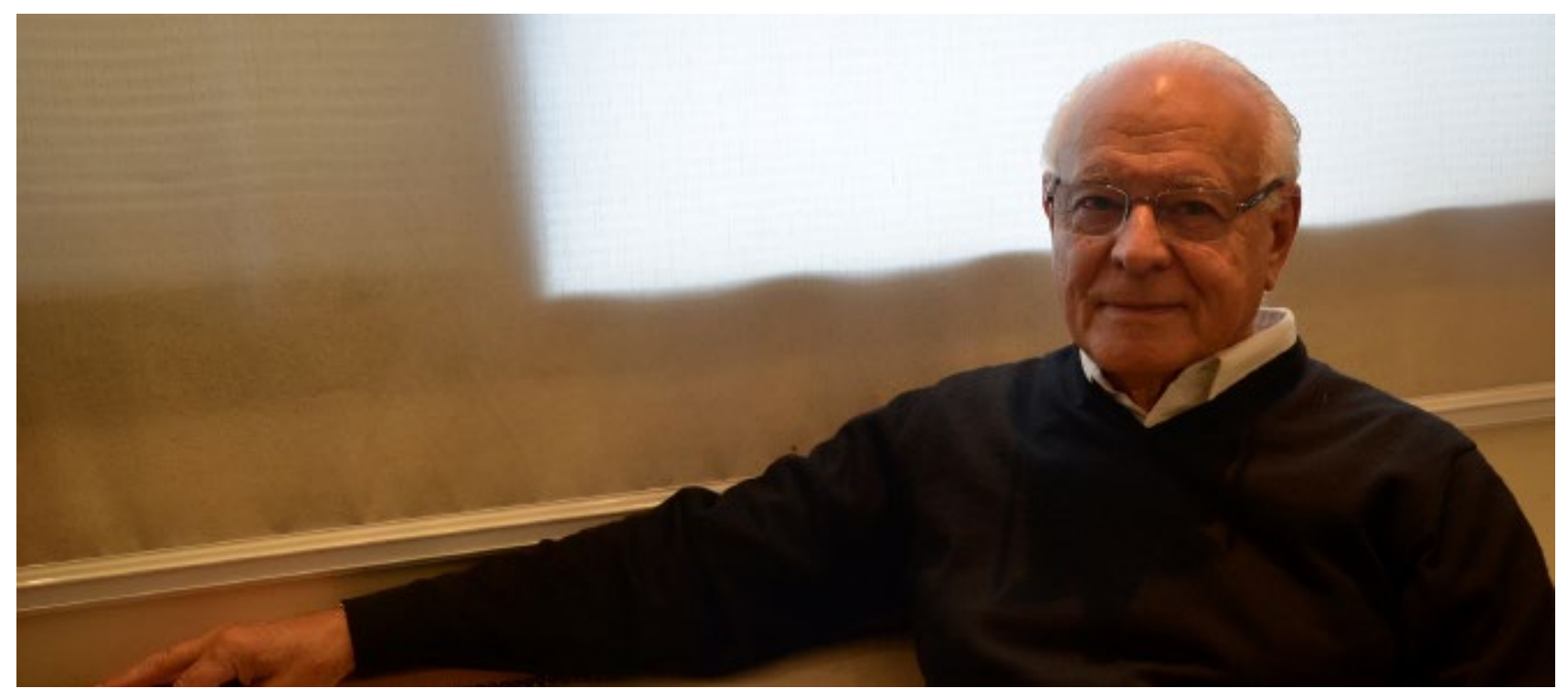

Para iniciarmos, o senhor poderia fazer uma breve apresentação de sua trajetória acadêmica no campo do Design?

Boa tarde, eu sou Norberto Chaves. Minha principal área de atuação é assessorar telecomunicações e marcas. Isto é, desenvolvo-os acerca de uns 30 anos em Barcelona, e, logo, adquiri uma quantidade de clientes, basicamente, na Argentina. Além disso, toda minha vida foi dedicada à docência, lecionando classes em temas específicos relacionados à minha atividade profissional, mas também sobre temas relacionados à cultura em geral, tema pelo qual sou apaixonado e por isso estou aqui, em Palermo, como estou em todos os anos.

\section{Como você entende que devem ser feitas as comunicações das marcas atualmente? Quais as principais dificuldades enfrentadas?}

Isso eu venho dizendo desde sempre, e neste seminário o reforcei bastante: a comunicação não pode ser pautada. É dizer, não pode ser normatizada. Não se podem criar normas generalizadas. $O$ desafio fundamental é buscar o máximo ajuste para cada caso, a cada necessidade e a cada cliente. Portanto, os meios essenciais são a formação comunicacional e cultural do assessor para poder interpretar muito bem cada caso e buscar a complexidade do cliente para evitar boicotar o projeto e, basicamente, o compreender. 
Ou seja, o desafio fundamental é a compreensão, a empatia pelos outros, e isso requer uma grande formação cultural. Não há outra escapatória.

\section{Quais são os principais motivadores para consumo e escolha das mar- cas pelos consumidores? Como você entende o consumo de marcas?}

Bom, para contemplar a essa pergunta haveria que se recorrer a livros. Pois, a teoria do consumo de marcas se formula, precisamente, na capacidade do usuário, do consumidor, em atribuir qualidades e no deslocamento de opção de compra para a fé, a confiança e a segurança que a marca lhe garante. Como não conheço um produto, levo um produto que assine determinada marca que já conheço. Essa marca tem duas funções: 1) legitimar a compra, dar segurança na compra e 2) agregar um valor ao usuário. Evidentemente, é prestigiante, certo? Então, nesse caso, o consumidor leva duas mercadorias: o produto legitimado pela marca e legitimação de si mesmo, por usar o produto assinado pela marca.

\section{O que mudou - e ainda pode mudar - na relação consumidor/marca em função da internet?}

Seu benefício eu não sei. É dizer, é como conjecturar, porque ainda não há, pelo menos na minha maneira de ver, resultados evidentes. Por um lado, a internet gera um fluxo de informação que pode relativizar a suposta "inopinabilidade" (a não opinião) das marcas. Como tem produzido opiniões políticas, opiniões de empresas. Ou seja, por um lado, pode ter um fator corretivo. Mas, por outro lado, pela própria natureza do meio, é um fator de propulsionar essa marca, porque essa marca também usa desse canal. Tanto a crítica, quanto a contestação ou a reticência ao marcário, como as próprias marcas, instrumentam isso. É dizer, inclusive eu sempre cito isso, um folheto de produtos para comerciais da companhia Nike, todo o folheto está passando sobre um sarcasmo e ironia sobre o consumista. E se chama "Tratamento de vícios" (Nike \#CoisaDaBoa) em que ridiculariza o consumo. As próprias marcas se dão conta de como estão trabalhando e, em vez de mudar o discurso, o usam a seu favor. Potencializam-no. É uma batalha sem fim. Cada medida que tome a resistência, para dizer assim, haverá outra medida tomada pela oferta. Teve um caso muito curioso em uma loja de Design em Barcelona em que o diretor, que é um célebre designer, uma pessoa super lúcida quanto ao produto - seleciona apenas produtos de altíssima qualidade -, viajou para 
os Estados Unidos e visitou a exposição de uma designer muito crítica que havia feito uns postais que ridicularizava o consumidor e dizia: "I shop the for I am", como que ironizando "compro por isso existo". Bom, o que fez o meu amigo, foi comprar os postais e usa-los em sua carteira.

\section{No mundo global e multicultural em que estamos vivendo, como uma marca pode construir e adaptar sua identidade cultural?}

Existe uma grande corrente e isso depende do tipo de produto. Existem produtos que são inexoravelmente globalizados e não têm declinações regionais. É dizer: o móvel que utilizamos está em todo o planeta. E não tem nenhum sentido adaptá-lo porque, justamente, o sistema de consumo é global. $O$ árabe usando a chilaba e um celular possui a mesma conduta que tu. Existem produtos que são globalizados porque correspondem a condutas globalizadas. Mas tem produtos que não, como as marcas globais em temas alimentícios que normalmente precisam fazer alguns ajustes. Incorporar dentro do menu de produtos, como o hambúrguer, é universal, assim como a Coca-Cola, mas no menu de Burger King ou McDonalds aparecem produtos que são apenas locais. E isso os experts em marketing sabem dosificar entre um extremo de máxima localização e máxima globalização está em cada caso. Por isso voltamos ao princípio, precisa-se administrar cada caso. Não se pode dar uma norma. É preciso saber em cada caso que peso tem o local. Alguns inventaram no "glocal", a mescla do global com local, mas as doses tem que determinar em cada caso, sem dúvida.

\section{O que considerar para definir a tipologia da marca e seu estilo?}

Esses dois conceitos, que seguramente extraíste de nosso texto, são chaves, porque os dois são identificadores. Identificadores no sentido em que se elege bem o tipo, ou seja, o modelo, e o estilo gráfico, o ajuste, se produz não só a identidade como a condição de comunicação. Pode ser que o perfil em si não requeira um símbolo, mas, pela extensão do nome, caia bem tê-lo para podê-lo comunicar. Então, essas são condicionantes que se precisa ter em conta para eleger o tipo. Uma vez elegido o tipo, agora se pensa a linguagem que vamos usar. Que não é a mesma linguagem do retro, do art decaux, renascentista ou clássico, que uma linguagem moderna ou fria palo seco da tipografia. Ou seja, os dois elementos são identificadores. 
Como se elege? De maneira muito simples: "Conhecendo perfeitamente ao sujeito, a empresa e sua condição de comunicação, e contrastando-os com os códigos de leitura social". E os códigos, porque me parece que para falar de estilo, os códigos: da informalidade, do classicismo, da elegância, da provação, do insólido, etc., etc., então vais administrando, elegendo os códigos adequados, para que o leitor veja o que queres que veja. É dizer, é possível ver, por exemplo, pelas marcas de moda que não há nenhuma que ocorra nenhuma transgressão. São marcas absolutamente rigorosas, muito elegantes e sóbrias. Não usam nenhum chiste, nem algo careta, nem nada disso. Quando se pensa o esporte, as roupas esportivas, aí sim se permitem outras coisas, mas na moda de alta costura, não existe nenhuma transgressão. E esses são os códigos que o desginer domina. $O$ público vê que essa marca é elegante. Não vê ironias, chistes, mas é vista sóbria, séria. Então, o ajuste tipológico, o ajuste estilístico, se produz porque o designer conhece os códigos sociais dos valores que precisa administrar e conhece os valores que deve administrar. É dizer, o repertório de valores que o cliente precisa transmitir e os códigos com que o público os lerão. E aí se volta mais uma vez à cultura. É uma comparação de dois universos que têm que ser harmônicos.

\section{Em um de seus textos, é mencionado que o Design se tornou uma en- tidade imaginária e que contribui para o culto da inovação. Ao seu ver, isso é negativo ou é algo natural que acabou ocorrendo em nossa so- ciedade?}

Claro, bom, isso temos em meu livro. A inovação tem duas dimensões que se precisa analisar. Trata-se de um desejo humano milenar. Ou seja, o ser humano tem que estar fazendo e refazendo o seu entorno para poder viver harmonicamente. Isso é uma verdade irrepreensível e insuperável. Portanto vai, permanentemente, reformulando seu ambiente para adaptar-se melhor e realizar-se em seu entorno. Mas, por outro lado, em outra escala, no nível antropológico, ou seja, no nível socioeconômico, a inovação é um instrumento de competitividade de mercado. As empresas que não inovam - que são inertes - perdem competitividade, porque o competidor avança com nova oferta, com novo critério de venda, com novo ponto de venda, etc. e vai captando mercado. Por conseguinte, o design nesse contexto tem 
um papel decisivo. Pois a cúpula: "design e inovação" é muito forte, muito sólida. $O$ designer inova desde as modificações de linguagem ou de forma, até inova em produtos absolutamente alternativos e inovadores, conforme apropriado. Ou seja, o design tem um papel chave na inovação. A inovação é mais ampla, porque pode haver a inovação tecnológica, inovação em critérios de gestão e vendas, há inovação em muitos campos. 0 design é a porta para um campo da inovação. Um produto da comunicação.

\section{Para finalizar, você poderia deixar uma mensagem aos designers e es- tudantes de Design, pois diante de tantas transformações, o que deve sempre se manter firme no campo do Design? Seria possível pensar a essência do Design?}

Claro. Muito boa a pergunta. É um pouco do que respondi a um dos últimos participante e o que colocava, basicamente, na primeira conferência. A mensagem, em geral, é: não crer que o design é autônomo, e que, a partir dele, vais estar instrumentado para produzir soluções eficazes em qualquer campo que trabalhes, porque esse design é não mais que um processo vazio que se nutre com todos os códigos. É dizer que se trata de uma formação cultural que permita manejar os códigos da forma, da estética e dos distintos códigos de linguagem comunicação, por um lado. E, também, uma formação intelectual, racional, que permita analisar cada caso e entende-lo. $O$ design é uma obra às cegas. $O$ que eu recomendo aos estudantes é que tomem o comando de suas próprias formações, não se acomodem exclusivamente às matérias que compõem seus cursos, as apreendam e tirem todo o partido possível, mas que não creiam que com isso já esteja resolvido todo o problema. Eles precisam ter uma vida cultural e intelectualmente muito intensa, para irem munindo-se de recursos para projetar. Então, todo o tempo que perdem em práticas que não acrescentam culturalmente ou de entretenimento vago, os estão empobrecendo. Estão perdendo o tempo, dizendo de outra maneira. Eu penso que esses dois blocos, a formação cultural e a formação intelectual, são irrenunciáveis e, sobretudo, são responsabilidades do estudante e não dos docentes. 